\title{
Determinants of the implementation of a new practice in hormonal contraception by Quebec nurses
}

\author{
Edith R. Guilbert, ${ }^{1}$ Jean Robitaille, ${ }^{2}$ Alexis C. Guilbert, ${ }^{3}$ and Diane Morin ${ }^{4}$ \\ ${ }^{1}$ Department of Obstetrics and Gynecology, Laval University, Quebec City, QC \\ ${ }^{2}$ Department of Agribusiness and Consumer Sciences, Laval University, Quebec City, QC \\ ${ }^{3}$ School of Education Sciences, Laval University, Quebec City, QC \\ ${ }^{4}$ Institut Universitaire de Formation et de Recherche en Soins, University of Lausanne, Lausanne, Switzerland
}

\begin{abstract}
In 2007, a task-shifting strategy through which a nurse, in collaboration with a community pharmacist, could start a healthy woman on hormonal contraception without a medical consultation was implemented in the province of Quebec. The purpose of this study was to identify factors associated with the 1) implementation of this new practice by nurses, 2) delay of implementation and 3) intensity of the practice. A validated questionnaire based on Rogers' theory of the diffusion of innovation was sent by postal mail or internet to all nurses that had successfully completed training in hormonal contraception since 2007, were registered at the College of nurses of Quebec and currently worked as nurses. The questionnaire was completed by 745 nurses between November 2011 and March 2012 for a response rate of 26.6\%. Results show that implementation of this new nursing practice was more successful when nurses had a high degree of cosmopoliteness, they perceived the new practice as simple, they worked in youth clinics and if health organizations where they worked were open to innovation, had low centralized decision-making and organizational slack. Various attributes of innovation, diffusion networks and characteristics of the organizations also explained intensity of the new practice. The findings suggest new avenues to simplify and scale up this strategy for use in other health organizations.
\end{abstract}

KEY WORDS: Contraception, nurses, task-shifting, task-sharing, prevention, unplanned pregnancy, determinants, innovation, implementation

\section{INTRODUCTION}

In the most recent Canadian Contraception Study (Black, et al., 2009), $65.3 \%$ of sexually active women reported that they always used a method of contraception in the past 6 months. The Enquête québécoise sur la santé de la population (Cazale \& Leclerc, 2010) found that $67 \%$ of sexually active women usually used contraception in the past 12 months. In 2006, the rate of induced abortion in Quebec was estimated to be the fourth highest in Canada after the Yukon, North-West Territories and Nunavut (Statistics Canada, 2010). It is known that limited access to effective contraception is associated with higher rates of unplanned pregnancies (Bertrand, Hardee, Magnani, \& Angle, 1995; Welsh, Stanback, \& Shelton, 2006).
We also know that in Quebec, in 2006, effective hormonal methods of contraception were available only on medical prescription. In addition, many women find it a challenge to access physician care. For example, the 2004 Canadian National Physician Survey (College of Family Physicians of Canada, 2005; College of Family Physicians of Canada \& the Canadian Medical Association, 2008) reported that $60 \%$ of practicing family physicians saw few or no new patients. Further, $25 \%$ of the population in Quebec (2003-2007) did not have a family physician (Gladu, 2007; Traoré \& Cazale, 2008) and this proportion was still at 21\% in 2010-2011 (Dubé-Linteau, Pineault, Lévesque, Lecours, \& Tremblay, 2013). Women aged 15-24 the demographic with the highest abortion rates (Statistics Canada) - were the most affected in that $32 \%$ in 2003-2007

\footnotetext{
Acknowledgements: We would like to thank Marc Simard and Bernard Candas at the National Institute of Public Health of Quebec for their consultation and guidance regarding the analysis of complex survey data and the interpretation of the findings. We also appreciate the insights of Andrew Dwyer at the Institut universitaire de formation et de recherche en soins, University of Lausanne, Lausanne, Switzerland for his revision of our English language.

Correspondence concerning this article should be addressed to Edith R. Guilbert, MD, National Institute of Public Health of Quebec, 915 avenue Wolfe, Quebec City, QC, Canada, G1V 5B3 E-mail: edith.guilbert@inspq.qc.ca
} 
(Traoré \& Cazale) and 26\% in 2010-2011 (Dubé-Linteau et al.) did not have access to a family physician.

In this context, the concept of task-shifting, described by the World Health Organization (WHO, 2009b) as a process of delegation or shifting of some tasks to less-specialized health workers, is a highly appealing approach to increase access to contraceptive use (World Health Organization \& UNAIDS, 2007). By reorganizing the workforce, task-shifting is expected to ease bottlenecks in service delivery and make more efficient use of existing human resources (World Health Organization \& UNAIDS).

Although the term "task-shifting" is relatively new, the concept had been applied for decades in family planning programs (Janowitz, Stanback, \& Boyer, 2012). A 1968 study compared the practice of intrauterine devices (IUD) insertion by physicians and nurses and found identical performance by both groups (Vaillant, Cummins, Richart, \& Barron, 1968). Indeed, most of studies conducted thereafter in developing and industrialized countries demonstrated the safety and efficacy of interventions such as providing hormonal contraceptives, prenatal and postnatal care, inserting IUDs and performing deliveries, C-sections and surgical abortions, when delivered by various non-physician health workers (community health workers, nurse assistants, etc.) (Armstrong \& Stover, 1994; Aziz \& Osman, 1999; Farr, Rivera, \& Amatya, 1998; Eren, Ramos, \& Gray, 1983; Gardner et al., 2008; Harper, Balistreri, Boggess, Leon, \& Darney, 2001; Hoke, et al., 2012; Jejeebhoy, et al., 2011; Lassner, et al., 1995; Mullany, et al., 2010; Parsons et al., 2013; Stanback, Mbonye, \& Bekiita, 2007; Warriner, et al., 2006; Warriner, et al., 2011). An increase in the number of providers can lead to significant gains in contraceptive use and may also free up the time of higher-level providers thus allowing them to handle more complex cases (Janowitz, Stanback, \& Boyer, 2012; Mwaikambo, Speizer, Schurmann, Morgan, \& Fikree, 2011). In line with these studies and WHO recommendations, the province of Quebec passed Bill 90, in 2002, allowing task-shifting between different categories of health professionals (Gouvernement du Québec, 2002). The first provincial application of this law was the Quebec model of Collaborative Agreement in Hormonal Contraception (CAHC) through which a nurse, in collaboration with a community pharmacist, can start a healthy woman on hormonal contraception (i.e., combined oral contraceptives, contraceptive patch and ring, progestin only pills or injectable contraceptives) without a medical consultation (Ordre des infirmières et infirmiers du Québec, 2007b). The model of CAHC was developed jointly by the College of physicians (CMQ), the College of nurses (OIIQ) and the College of pharmacists (OPQ), with the collaboration of the National Institute of Public Health (INSPQ) and the Ministry of Health and Social Services of Quebec (MSSS) (Guilbert, Ménard, Mercier, \& Caron, 2007).

The first Quebec model of CAHC was launched in 2007 (Ordre des infirmières et infirmiers du Québec, 2007b). It allowed nurses and pharmacists to start women on hormonal contraception for a period of 6 months. In practice, for in- stance, if a 16-year-old adolescent needs hormonal contraception, she can visit her school nurse who will evaluate her health, give her counseling on all contraceptive methods, verify her contraindications to the desired contraceptive method, check her body mass index and blood pressure (a pregnancy test may also be performed if necessary). A woman with an absolute or relative contra-indication is referred to a physician. However, for all other cases, nurses tailor their counseling to the chosen contraceptive method. The nurses then, sign a "liaison form" (prescription-like form) with the name of the recommended contraceptive and gives it to the woman. The liaison form is linked to the health centre where the nurse works and includes the name and telephone number of a collaborating physician who can be contacted for questions or clarifications. Then, the woman goes to the pharmacy of her choice and hands on the liaison form to the pharmacist, who will check the pharmaceutical profile of the woman and give her the contraceptive drug for a period of 6-months. Within that period, the woman is expected to obtain prescription renewal from a physician.

Because of various legal constraints and with the aim of promoting interdisciplinary collaboration, the CMQ requires physicians of each health care organization or clinic to adopt their own independent local CAHC in compliance with the provincial model. The provincial model serves as a guide that can be adapted locally. Therefore, in every local Health and Social Service Organization (so called CSSS - 94 CSSS in the province of Quebec), physicians must agree to shift this new task to nurses and then agree on the content of their own local CAHC including the designation of responding physicians. Nurses usually targeted by local CAHCs in CSSSs are those working in schools, youth clinics, maternal and child health clinics, family planning clinics and outpatient clinics. Only following CAHC approval, can the trained nurses legally start women on hormonal contraception. The same mechanism applies to nurses who work in settings such as hospitals, family medicine groups (GMF), medical clinics, women's health centers or settings outside the public health system (i.e., colleges, universities, etc.). In these settings, a specific CAHC must be adopted by one or more physicians regularly in contact or working with these organizations. A copy of each local CAHC must be sent to the OPQ which publishes it on a website allowing the community pharmacists to verify that the liaison forms are linked to valid CAHCs (for more information visit www.inspq.qc.ca/contraception).

Along with the launch of the first provincial model of CAHC in 2007, a 7-hour training program in hormonal contraception was initiated and delivered by two trainers (a physician and a nurse). In 2009, the provincial CAHC model was updated (Ordre des infirmières et infirmiers du Québec, 2009b) in line with the new eligibility criteria for contraceptive use published by the World Health Organization (2009a) and the training was expanded to a 10-hour e-learning program comprising 18 modules. Recently, the training was updated again, following the 2012 update of the CAHC model (Ordre des infirmières et infirmiers du Québec, 2012b) according to CDC 
Table 1. Constructs and dimensions of the theory of the diffusion of innovation (Rogers, 2003)

1. The attributes of innovation: relative advantage, compatibility, complexity (or simplicity), triability and observability.

2. The characteristics of adopters: innovators (venturesome), early adopters (respect), early majority (deliberate), late majority (skeptical) and laggards (traditional). The adopters can also be defined by their socioeconomic, personality, communication characteristics and their cosmopoliteness.

3. The diffusion networks: modes of communication, type of diffusion system, characteristics of opinion leaders and change agents.

4. The characteristics of the organizations where the innovation takes place: types of innovation-decision, structure of the organization, organizational innovativeness, innovation process.

5. The consequences of innovation: desirable versus undesirable, direct versus indirect, anticipated versus unanticipated.

guidelines (Centers for Disease Control and Prevention, 2010; Centers for Disease Control and Prevention, 2011; Centers for Disease Control and Prevention, 2012). This updated training now allows nurses and pharmacists to start women on hormonal contraception for a period up to 1 -year and enables them to provide the initial consultation and prescription of an IUD before insertion by a physician or a nurse-practitioner.

Given that starting women on hormonal contraception without medical consultation was a new practice for nurses and pharmacists in Quebec, we considered it an innovation. The implementation of innovative models of service-delivery is challenging (Groulx \& Direction de santé publique de l'Agence de la santé et des services sociaux de la Montérégie, 2007; World Health Organization, 2009b). As previously reported (Guilbert, Guilbert, et al., 2011; Guilbert, Robitaille, Guilbert, Morin, \& and the Group of experts in Family Planning of the National Institute of Public Health of Quebec, 2013), impediments to implementation include: the high degree of inter-professional collaboration required by the CAHC; the difficulty in sharing tasks previously "owned" by physicians; and the requirement of an independent CAHC in each health, education or other organization. These difficulties can lead to imperfect replication of the provincial model. Moreover, nurses who are at the centre of this strategy face organizational constraints; some feel ill-prepared for these new tasks and insufficiently supported by physicians, pharmacists and health organization administrators (Guilbert, Robitaille, et al., 2013).

\section{The present study}

As a part of the evaluation of this new task-shifting strategy it was important to understand the challenges faced by nurses to further improve the implementation strategy. Therefore, with the aim of evaluating the determinants of implementation of this new practice, INSPQ conducted a study. Our goals were: (1) to identify the factors associated with implementation of this new practice by nurses (specifically, which factors influence a nurse to begin the practice of starting women on hormonal contraception?); (2) to consider factors that can delay implementation (specifically, which factors influence how rapidly a nurse implemented the new practice after training?); and (3) to determine the intensity of the practice (specifically, which factors influence a nurse to do this practice, very often on a monthly basis?).

\section{METHODS}

\section{Conceptual framework}

The concept of diffusion of innovation first developed by Rogers (2003) defines innovations as ideas or practices perceived as new by practitioners (Greenhalgh, Robert, Macfarlane, Bate, \& Kyriakidou, 2004). Several research areas have provided evidence relevant to the diffusion of innovations in health service organizations (Greenhalgh et al.). This approach has been tested in family planning in that Rogers et al, 1999 studied the diffusion of family planning behaviours through an entertainment-education radio soap opera in Tanzania. The conceptual framework of the diffusion of innovation seeks to explain how, why, and at what rate new ideas and technology spread through cultures; it is broadly influenced by five elements or constructs as presented in Table 1. These elements are: attributes of innovation; characteristics of adopters; diffusion networks; characteristics of innovative organizations; and consequences of innovation. Each element works with the others (Rogers). Enabling change is not just dependent on the people who are supposed to change. An extensive literature review (see Greenhalgh et al.) expanded this model and assessed the robustness of its constructs and dimensions.

As noted by Greenhalgh et al. (2004), the interaction between the innovation, the intended adopter(s), and a particular context determines the adoption rate and therefore may influence implementation. In the case of the new practice by the nurses under study here, their expanded role was conditional on the agreement of a local CAHC (Ordre des infirmières et infirmiers du Québec, 2007b; Ordre des infirmières et infirmiers du Québec, 2009b; Ordre des infirmières et infirmiers du Québec, 2012b). It has also been shown that contextual factors (e.g. intra-organizational structure, inter-organizational dynamics) may affect user's adoption of an innovation and particularly so in relation to the rules and resources that are introduced by this innovation (Lewis \& Seibold, 1993). Implementation, by its very nature, is also a social process that is intertwined with the context in which it takes place (Damschroder et al., 2009). 


\section{Study population}

Nurses were eligible for entry in the study if they: had successfully completed training in hormonal contraception; were registered at the College of nurses of Quebec; and currently worked as nurses. All nurses who were trained in hormonal contraception from March 2007 to September 30, 2011 were invited to participate in the study. Data collection took place between November 25, 2011 and March 16, 2012. The study was approved by the Ethical Review Board of Laval University, Quebec, Canada.

Given that more than 3, 000 nurses had successfully completed the training at the time of planning this survey and that our anticipated response rate was $33-45 \%$, we expected to receive 900-1,350 completed questionnaires (Robitaille, 2011).

\section{Data collection}

Since the project launch in March 2007, the INSPQ has kept a registry of nurses who successfully completed training in hormonal contraception. In the fall of 2011, with the collaboration of the College of nurses of Quebec, NIPHQ, we obtained the postal and/or e-mail addresses of these accredited nurses. Whenever possible, e-mail invitations including the online consent form and the research questionnaire (on Lime Survey platform) were sent to potential respondents. Others were contacted by post with an invitation letter, two copies of the consent form, the research questionnaire and a pre-addressed and pre-paid response envelope. Reminders were sent one week and one month after the first contact per Dillman's tailored design method (Hoddinott \& Bass, 1986; Rosenbaum \& Lidz, 2007). A complete set of documents was sent by post 2 weeks after the second reminder to the e-mail cohort of nurses. All documents were French-written.

Paper questionnaires were reviewed for completion and participants were contacted to complete missing answers or unclear responses. Paper questionnaires were up-loaded twice, independently, in separate Excel data banks and were compared for accuracy before merging with the data from the electronic questionnaires.

\section{Questionnaire development}

Based on group discussions and interviews with nurses, a questionnaire was developed in 2009 according to the theory of the diffusion of innovation (Rogers, 2003). The first draft of the questionnaire was revised by a group of nurses and physicians who are experts in contraception. A pretest was conducted among five practicing nurses who suggested modifications. The revised questionnaire went through an initial metric validation. A second metric validation took place in 2010 following reformatting per the results of the first validation. To assess the validity of the questionnaire, we did principal component and factor (i.e., Varimax) analyses. Internal consistency of theoretical constructs was measured with Cronbach's alphas. As presented in Table 2, most constructs exhibited Cronbach's alphas greater than 0.70. Con- structs for which Chronbach's alphas were under 0.70 were redefined for the final version of the questionnaire. In addition, all factors with Eigen values superior to 1 were kept in the final questionnaire. Results of this study have been previously published (Guilbert, Morin, et al., 2011). The questionnaire was then considered valid and deemed ready for a more extensive study.

\section{Measures}

\section{Dependent variables}

Three variables selected as outcomes of interest were constructed from the threeaforementioned questions. The first outcome was related to the implementation of the new practice of starting women on hormonal contraception. We defined implementation of the new practice as the clinical activities related to starting women on hormonal contraception. The question regarding this outcome included four response options: (1) I do this practice under a collaborative agreement; (2) I do this practice under a collaborative agreement but without signing the liaison form; (3) I do this practice out of a collaborative agreement; and (4) I do not practice this activity.Respondents who selected one of the first three options were deemed to be implementing the new practice whereas those who selected no practice were classified as non implementers. The resulting variable was dichotomous: implementing this practice versus not implementing this practice. The second outcome measured the rapidity of implementation of this practice after training. To assess this, we performed a subtraction of the year when the training was completed to the year when the practice was begun. When the practice was begun in the same year as the training, the delay was zero. This variable was a continuous variable. The third outcome dealt with the intensity of the practice. It was assessed by the number of clients started on hormonal contraception by a nurse in a typical month (continuous variable).

\section{Independent variables}

Independent variables were obtained for each dimension of Rogers' theory (Table 3). For Likert-type questions, a score was obtained for each item and scores were averaged for each dimension. For dichotomous questions such as those concerning past experience and re-invention, a score of 0 or 1 was assigned to No and Yes answers, respectively; an average score of all items was then developed for these dimensions.

Variables related to external factors, the so-called external variables, included; socio-demographic variables (age less than 30 years, $30-39$ years, $40-49$ years, $50-59$ years, 60 years and over); marital status and living arrangements (married with a spouse, married without a spouse, single with a spouse, single without a spouse, other with a spouse, other without a spouse); level of education (college, university, bachelor, master or doctorate degree); organization where the nurse worked (CSSS, GMF/ women's health centre, hospital settings, educational institutions/youth protection centre, other settings 
Table 2. Results of the factor analysis and internal consistency

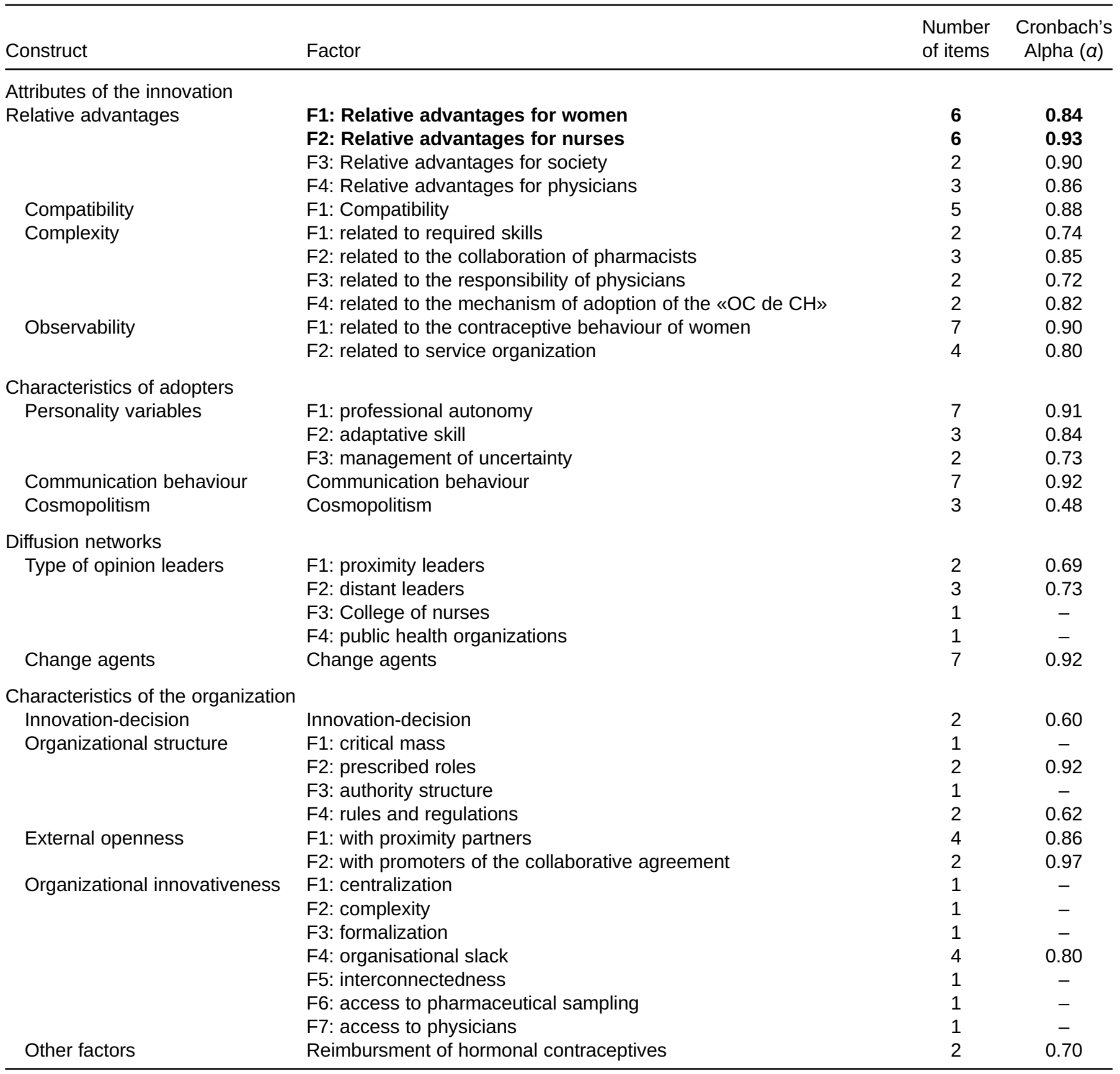

(aboriginal reserve, pharmacy, other); sector of practice (youth clinic, school health clinic, other (outpatient clinic, family planning clinic, public health, standby team, other); and region of practice (region of Montreal, urban region around Montreal ((Laval and Montérégie), rural regions around Montreal (Estrie, Outaouais, Lanaudière, Laurentides), region of Quebec city, regions around Quebec city (Bas-Saint-Laurent, SaguenayLac-Saint-Jean, Mauricie et Centre-du-Québec, ChaudièreAppalaches), remote areas (Abitibi-Témiscamingue, CôteNord, Gaspésie-Îles-de-la-Madeleine, Nunavik, Terres-Criesde-la-Baie-James).
External variables also included: employment and training variables (working status at the time of the survey (part-time job, full time temporary status, full time permanent status and temporary leave of absence); year of training (2007 to 2011), type of training (traditional versus on line); and working status at the time of training (practicing nurse versus student in nursing or other). Variables related to coverage of contraceptives by the public or private drug insurance plans were also included in external variables. 
Table 3. Constructs, dimensions and factors of the theory of the diffusion of innovation and external factors included in the questionnaire

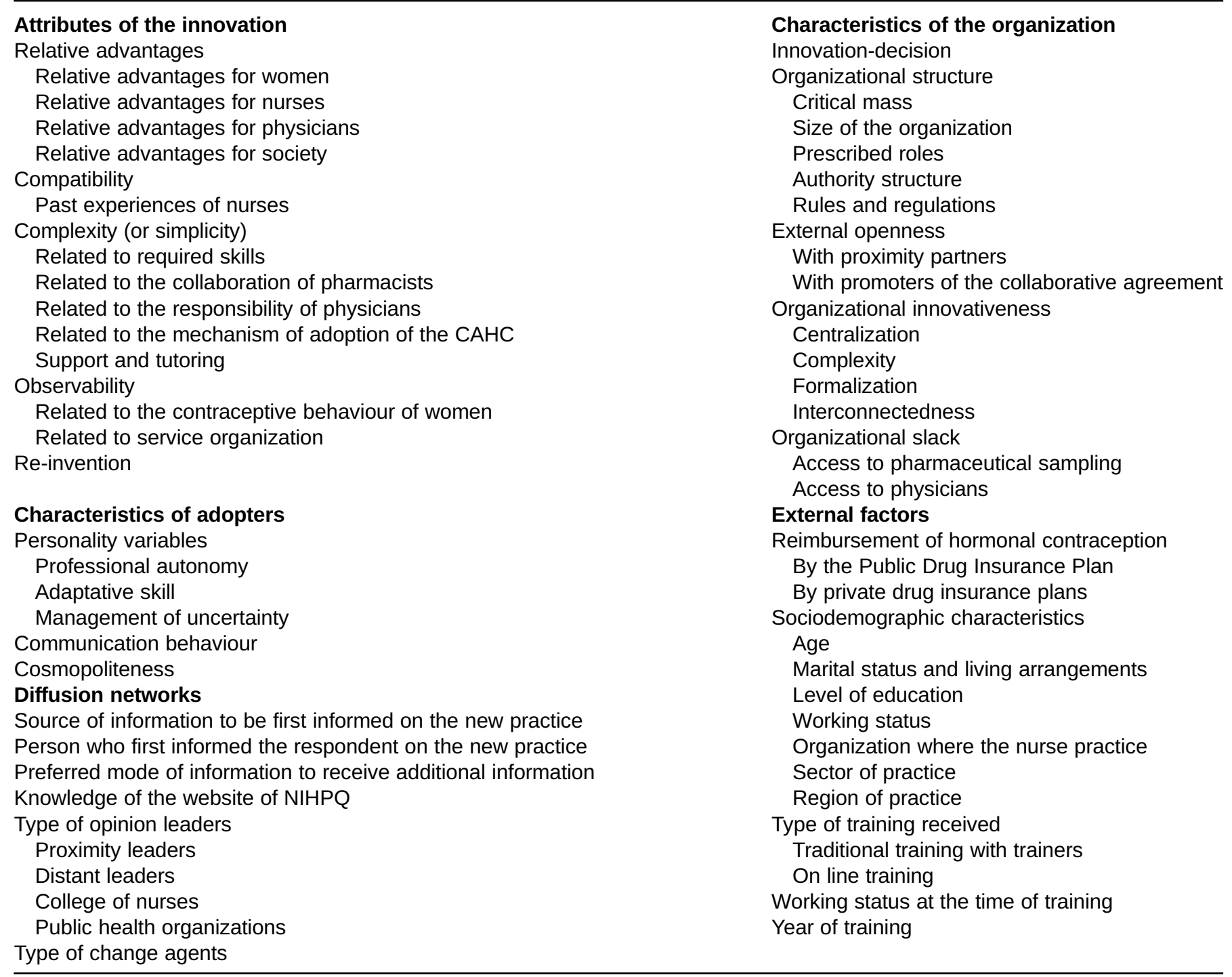

\section{Statistical procedures}

For each outcome of interest, analysis was first performed including all variables with subsequent analyses restricted to the variables specifically related the theory of diffusion of innovation. This strategy was adopted to specifically assess the respective influence of Rogers' variables with and without external variables.

For the first outcome, the implementation of the new practice of starting women on hormonal contraception (dichotomous dependent variable), we used binomial logistic models selecting variables with a backward stepwise method. Model fitting stopped when the highest value of the Nagelkerke $\mathrm{R}^{2}$ and the highest percentage of valid predictions were reached (Greene, 2012). The significance level for all variables was set at $\mathrm{p}<0.05$.

For the second and third outcomes of interest (intensity of the new practice and delay of implementation of the new practice) (continuous dependent variables), the sample was restricted to the participants who had implemented the practice. Analysis was first performed including all the variables. Then a second analysis was restricted to the variables related to Rogers' theory. For these outcomes, we used a multiple OLS linear regression model selecting variables with a backward stepwise strategy. Model fitting stopped when the highest value of the adjusted $\mathrm{R}^{2}$ was reached (Greene, 2012). The significance level for all variables was set at $\mathrm{p}<0.05$. All statistical analyses in this study were performed with IBM-SPSS version 20.0.0 (2011).

\section{RESULTS}

Socio-demographic, training and working characteristics of the respondents are described elsewhere (Guilbert, Rousseau, et al., 2013). A total of 3,043 nurses were invited to participate 
Table 4. Odds ratio from binomial logistic regression estimates of selected variables predicting the hazard of implementing the new practice of starting women on hormonal contraception

\begin{tabular}{|c|c|c|}
\hline & $\begin{array}{l}\text { Model } 1 \\
\text { Variables of the diffusion } \\
\text { of innovation and } \\
\text { external variables }\end{array}$ & $\begin{array}{l}\text { Model } 2 \\
\text { Variables of the diffusion } \\
\text { of innovation only }\end{array}$ \\
\hline Characteristic & $\begin{array}{l}\text { Regression coefficient } \\
\text { (Standard error) }\end{array}$ & $\begin{array}{l}\text { Regression coefficient } \\
\text { (Standard error) }\end{array}$ \\
\hline \multicolumn{3}{|l|}{ Characteristics of adopters } \\
\hline Cosmopoliteness & $1.202(0.089)^{*}$ & - \\
\hline \multicolumn{3}{|l|}{ Diffusion networks } \\
\hline Favours interpersonal contact to obtain additional information & $0.276(0.426)^{* *}$ & $0.265(0.374) * * *$ \\
\hline Opinion leaders & - & $1.196(0.078)^{*}$ \\
\hline \multicolumn{3}{|l|}{ Characteristics of the organization } \\
\hline \multicolumn{3}{|l|}{ Sector of practice } \\
\hline Youth clinics & $1.000 * * *$ & - \\
\hline School health clinic & $0.443(1.098)$ & - \\
\hline Other settings & $0.083(1.045)^{*}$ & - \\
\hline Constant & $0.157(1.464)$ & $0.131(0.658)^{* *}$ \\
\hline Nagelkerke $\mathrm{R}^{2}$ & 0.312 & 0.186 \\
\hline \multicolumn{3}{|l|}{ Log-likelihood ratio test for the exclusion of variables } \\
\hline$x^{2}$ & 79.627 & 49.138 \\
\hline Prob. $>X^{2}$ & $<0.001$ & $<0.001$ \\
\hline N (participants) & 423 & 436 \\
\hline
\end{tabular}

* Significant at $\mathrm{p}<0.05 ; * \mathrm{p}<0.01 ; * * \mathrm{p}<0.001-=$ Not applicable

$\dagger$ Reverse coding of Complexity

in the study. After excluding those found non eligible and questionnaires returned because of an invalid address, a total of 745 questionnaires out of 2805 eligible nurses were available for analysis (response rate of 26.6\%). Given these numbers, the different statistics computed for this sample had a margin of error of $\pm 3.2 \%$ within a CI of $95 \%$. Fifty-seven percent (57.3\%) of respondents declared that they had implemented the new practice of starting women on hormonal contraception. Most of them (96\%) did so under a CAHC using " liaison forms " and implemented within two years of training $(85 \%)$ serving an average of 5.6 women (SD: 9.5 ; median: 3.5) per month.

\section{Determinants of implementation of the new practice}

As shown in Model 1 (Table 4), seven variables were selected explaining $31 \%$ of score variance of the implementation outcome. Nurses who worked in youth clinic had more chances to begin this new practice than those working in school health clinic (not significant: $\mathrm{p}=0.443$ ) or other settings (significant: $\mathrm{p}=0.083$ ). Those who stated that they favoured interpersonal contact to receive additional information on CAHC were 3.6 times less prone to begin this practice. Those who perceived external openness or innovativeness in the organization where they worked had significantly more chances (28\% and $24 \%$ respectively) to implement the practice than those who did not perceive such attributes. Cosmopoliteness (i.e., the degree to which an individual is oriented outside a social system (Rogers, 2003)) and perceived simplicity (opposite of complexity) (i.e., the degree to which an innovation is perceived as relatively easy to understand and use) were also significantly and positively associated with the implementation of the new practice but to a lesser degree $(20 \%$ and $13 \%$, respectively). Although not significant, perception that the decision to adopt this practice was taken on a voluntary basis was also positively associated with the implementation of the new practice.

When the external variables were removed (Model 2, Table 4), four variables of the Rogers' theory remained, with a total of $18.6 \%$ score variance explained. The variables were: favouring interpersonal contact to receive additional information on CAHC (negative association), organizational innovativeness (positive association), perceived simplicity (positive association) and perceived influence of opinion leaders (positive association). Additional analysis (supplemental data not shown) indicated that among the factors included into the dimension of organizational innovativeness, low centralization of decisions 
Table 5. Regression coefficients from OLS multiple regression analysis of selected variables predicting the delay of adoption of the new practice of starting women on hormonal contraception

\begin{tabular}{|c|c|c|}
\hline Characteristic & $\begin{array}{c}\text { Model } 1 \\
\text { Variables of the diffusion } \\
\text { of innovation and external variables } \\
\text { Regression coefficient } \\
\text { (Standard error) }\end{array}$ & $\begin{array}{l}\text { Model } 2 \\
\text { Variables of the diffusion of } \\
\text { innovation only } \\
\text { Regression coefficient } \\
\text { (Standard error) }\end{array}$ \\
\hline \multicolumn{3}{|l|}{ Attributes of the innovation } \\
\hline \multicolumn{3}{|l|}{ Characteristics of the organization } \\
\hline Organizational structure & & $-0.105(0.043)^{*}$ \\
\hline Size of the organization less than 50 employees & & $-0.359(0.178)^{*}$ \\
\hline \multicolumn{3}{|l|}{ Other factors } \\
\hline \multicolumn{3}{|l|}{ Year of training } \\
\hline $2007-2009$ & $0.580(0.118) * * *$ & - \\
\hline F value & $11.437 * * *$ & $7.059 * * *$ \\
\hline N (participants) & 362 & 367 \\
\hline
\end{tabular}

* Significant at $\mathrm{p}<0.05 ; * * \mathrm{p}<0.01 ; * * \mathrm{p}<0.001-=$ Not applicable

and organizational slack in terms of resources, premises, and schedules were positively associated with the implementation of the practice. Regarding opinion leaders, the managers and administrators in charge of the nurses were the most influential as opposed to leaders external to the organization.

\section{Determinants of the delay in implementation of the new practice after completing training}

As shown in Table 5, model 1 selected four significant variables explaining $10.4 \%$ of score variance of the delay of the implementation of the new practice. The delay between training and the implementation of the new practice was $58 \%$ and $53 \%$ longer when the nurse had been trained in 2007-2009 versus 2010-2011 and lived in a remote area of the province, respectively. On the contrary, the delay was $39 \%$ and $53 \%$ shorter when the nurse had had previous experiences compatible with the new practice and had introduced re-inventive strategies in her practice (Re-invention is defined as the degree to which an innovation is changed or modified by a user in the process of adoption and implementation of an innovation (Rogers, 2003). As an example of re-inventive strategies, nurses would re-initiate hormonal contraception when their client could not find a physician, after 6 months, to obtain an individual prescription of hormonal contraceptives).

When the external variables were removed (Model 2, Table $5)$, three significant variables of the Rogers' theory remained, explaining $4.7 \%$ of score variance: a shorter delay was significantly associated with a perception of favourable organizational structure $(-11 \%)$, a small size of the organization $(-36 \%)$ and reinvention $(-88 \%)$.

\section{Determinants of the intensity of the new practice}

As shown in Table 6, model 1 selected 7 significant variables explaining $42 \%$ of score variance in the intensity of the new practice. The intensity in performing the new practice was $37 \%, 12 \%$ and $8 \%$ higher when the nurse had had previous experiences compatible with the new practice, observed the effects of the new practice, and perceived organizational innovativeness, respectively. The concept of reinvention - the degree to which an innovation is changed or modified by the user in the process of its adoption and implementation increased the intensity of practice by $106 \%$. However, nurses who worked in sectors (outpatient clinic, family planning clinic, public health, flying squad, other) other than a youth clinic $(-82 \%)$, those from the Center-East of the province (Regions 01, 02, 03, 04, 12) $(-19 \%)$ and those who favoured electronic contact to obtain additional information (-20\%) were less likely to practice intensively.

When the external variables were removed (Model 2, Table 6), six significant variables of the Rogers' theory remained, explaining $27.9 \%$ of score variance. The intensity in doing this new practice was higher when nurses perceived the practice as simple $(+6 \%)$, had mentoring and support $(+21 \%)$, observed the effects of the new practice $(+17 \%)$, introduced re-inventive strategies in their practice $(+166 \%)$ and were influenced by opinion leaders $(+6 \%)$. On the contrary, intensity decreased by $4 \%$ when nurses perceived that the decision to adopt this practice was voluntary. Additional analysis (supplemental data not shown) indicated that intensity was linked to the fact that nurses observed an increased number of adolescents consulting them for contraception and stating they 
Table 6. Regression coefficients from OLS multiple regression analysis of selected variables predicting the intensity of the new practice of starting women on hormonal contraception

\begin{tabular}{|c|c|c|}
\hline Characteristic & $\begin{array}{c}\text { Model } 1 \\
\text { Variables of the diffusion of } \\
\text { innovation and external variables } \\
\text { Regression coefficient } \\
\text { (Standard error) }\end{array}$ & $\begin{array}{l}\text { Model } 2 \\
\text { Variables of the diffusion of } \\
\text { innovation only } \\
\text { Regression coefficient } \\
\text { (Standard error) }\end{array}$ \\
\hline \multicolumn{3}{|l|}{ Attributes of the innovation } \\
\hline Previous experiences & $0.372(0.146)^{*}$ & \\
\hline Observability & $0.118(0.031)^{* * *}$ & $0.172(0.033)^{* * *}$ \\
\hline Reinvention & $1.055(0.207)^{* * *}$ & $1.657(0.213)^{* * *}$ \\
\hline \multicolumn{3}{|l|}{ Diffusion networks } \\
\hline Favours electronic contact to obtain additional information & $-0.195(0.075)^{*}$ & - \\
\hline Opinion leaders & - & $0.055(0.023)^{*}$ \\
\hline \multicolumn{3}{|l|}{ Sector of practice } \\
\hline Other settings & $-0.821(0.079)^{* * *}$ & - \\
\hline \multicolumn{3}{|l|}{ Region of practice } \\
\hline Center-East of the province & $-0.189(0.078)^{*}$ & - \\
\hline Constant & $1.748(0.270)^{* * *}$ & $0.666(0.292)^{*}$ \\
\hline Adjusted $\mathrm{R}^{2}$ & 0.425 & 0.279 \\
\hline F value & $39.142 * * *$ & $24.560 * * *$ \\
\hline N (participants) & 362 & 367 \\
\hline
\end{tabular}

* Significant at $\mathrm{p}<0.05 ; * * \mathrm{p}<0.01 ; * * * \mathrm{p}<0.001-=$ Not applicable

$\dagger$ Reverse coding of Complexity

practiced safer sex. As for reinvention, three variants of the practice were noted to be related to intensity: the fact that nurses re-issued another "liaison form" 6-months after the initial form (primarily because women could not identify a physician to provide them with a renewal prescription), handled pharmaceutical samples of contraceptive drugs, and drug substitution by pharmacists. Regarding opinion leaders, those external to the organization were the most influential for intensity as opposed to managers and administrators in charge of the nurses.

\section{DISCUSSION}

Introducing innovative approaches into the daily routines of health professionals is a complex process. Many interventions found to be effective in health services research studies often fail to translate into meaningful patient care outcomes across multiple contexts (Damschroder et al., 2009). Some estimate that two-thirds of organizations' efforts to implement change are unsuccessful (Greenhalgh, 2004). Van Achterberg, Schoonhoven, and Grol (2008) argue that implementation of evidence in nursing practice, such as compliance to hand-hygiene prescriptions, delivery of smoking-cessation interventions or discouraging ineffective use of restraints for preventing falls in nursing home residents have been largely ineffective. In the present study, the observation that $57.3 \%$ of respondents have implemented the new practice of starting women on hormonal contraception, within two years of their training in hormonal contraception, is an encouraging result. Comparable or better results have been attained with nurses in settings across a broad range of practices (Bowen, Stanton, \& Manno, 2012; Montufar, Morales, Vernon, Brambila, \& Solorzano, 2005; Oppewal, Lamanna, \& Lee Glenn, 2006; van der Weide \& Smits, 2004; While \& Biggs, 2004).

Implementation strategies are expected to be more successful when they match relevant determinants, are linked with relevant theoretical insights, and are supported by evidence for either the theory or the effectiveness of the strategy itself (van Achterberg et al., 2008). The implementation of CAHCs in health organization as well as the new practice of starting women on hormonal contraception by nurses was supported by evidence concerning the effectiveness of this type of strategy and the legal foundation for this established in 2002. However, theoretical insights concerning implementation per se emerged during the planning of the survey. Therefore, the determinants of implementation according to Rogers' theory are critical to enhance further implementation. First, this study demonstrated that nurses working in youth clinics are more likely to implement this new practice and to use it more frequently 
than those in other settings. This finding is consistent with the aim of the strategy which was directed to nurses in youth clinics of CSSSs. Youth clinics in Quebec are available in almost all CSSSs and offer a variety of services to women less than 18-22 years depending on the availability of resources. At of early 2012, 95\% (89/94) of CSSSs had adopted a CAHCs. Yet, penetration of the new practice in other sectors has not been as successful. Only 22\% (49/227) of GMFs had adopted a local CAHC - GMFs being major distributors of health services for adults. Therefore, the results of this study may serve to generate ideas on making adjustments and adapting it to expand GMF implementation. Partners and stakeholders involved in the implementation of this task-shifting strategy are presently exploring new avenues to optimize this strategy based on these determinants.

Determinants of Rogers' theory appear to better explain the intensity of new practice $\left(\mathrm{R}^{2}(\right.$ model 1$\left.)=0.425\right)$ compared to its implementation $\left(\mathrm{R}^{2}(\right.$ model 1$\left.)=0.104\right)$ or rapidity of implementation $\left(\mathrm{R}^{2}(\operatorname{model} 1)=0.312\right)$. Interestingly, among these determinants, the attributes of innovation also act differently depending on the outcome, being much more involved in the intensity of practice than in its implementation. Notably, perceived simplicity is the sole attribute of innovation implicated with implementation of new practice while previous experience and reinvention are associated with short delays in implementation. Previous experience, observability, reinvention, perceived simplicity, mentoring and support are all related to intensity. For implementation, the simpler the new practice is perceived to be, the higher the proportion of nurses implementing it will be. In a study of the implementation of a local campaign for Healthier Babies among chapter directors of the National March of Dimes Birth Defects Foundation in the United States (US), simplicity was also identified as the most critical determinant in predicting level of local implementation (Goldman, 1994). According to Rogers (2003) and Greenhalgh et al. (2004), innovations that are perceived by key players as simple to use are more easily adopted. It is not clear from our study whether the perceived simplicity/ complexity dimension (measured by a global variable) relates specifically to the practice of starting women on hormonal contraception or to factors linked to the organizational context. Engaging in this new practice takes time as it requires more than 10 hours of training. Yet its application is facilitated by the use of a pre-designed questionnaire (Ordre des infirmières et infirmiers du Québec, 2007a; Ordre des infirmières et infirmiers du Québec, 2009a; Ordre des infirmières et infirmiers du Québec, 2012a) which supports nurses in their consultations with women. However, the organizational context may represent a challenge for nurses to put their training into practice. Rogers posits that innovation in an organizational setting is assimilated more easily when there are fewer barriers to response to overcome. Further results on organizational constraints may sustain this hypothesis and further support the concept of simplicity reported in the present study.

As shown in previous studies (Greenhalgh et al., 2004;
Lewis \& Seibold, 1993; Rogers, 2003), observability and reinvention are highlighted in this study as they are associated with shorter delays in implementation (reinvention only) and with intensity. Whereas some innovations may be difficult to observe (Rogers), others like this new practice are easily detected. Once nurses offer this service in youth clinics, young women present for contraception, obtain a desired contraceptive method and return for follow-up. Such a positive reinforcement of the new practice may develop nurses' confidence in their abilities and enhance the intensity of their practice. In terms of reinvention, the association was almost twice stronger with intensity than with delay, supporting that it is much more influential on the efficiency of this practice than other aspects of it. Reinvention appears to be characteristic of the implementation stage of the innovation-decision process (Rogers). Its perception among researchers varies. For some, lack of fidelity and lack of uniformity in the form of the innovation-in-use has been viewed as evidence of successful adaptation whereas for others, this lack was viewed as a diluting effect which should be guarded against (Lewis \& Seibold). In our study, reinvention was related to the facts that nurses would re-initiate and thus, re-issue another "liaison form" 6 months after the first one and that pharmacists changed the contraceptive drug because of cost (on the opposition to original drugs, generics are fully covered by the Provincial Drug Insurance Plan) or shortage of drug. The provincial model of CAHC of 2012 has now integrated this nursing practice and allows the initiation of contraception for a full year (Ordre des infirmières et infirmiers du Québec, 2012b; Gouvernement du Québec, 2013). Further, a new law allowing drug substitution by pharmacists was passed in 2013 (Gouvernement du Québec). Therefore, reinvention in the context of this study has enhanced the initial framework of access to contraceptives rather than limiting it.

The present study identified previous experience as associated with both the rapidity of implementation and the intensity. In the case of starting women on hormonal contraception, several nurses, and particularly those working in youth clinics, had prior experience in counseling women about contraception and in handling pre-signed prescriptions for contraceptives or treatment of sexually transmitted infections. Therefore, it was easy for them to quickly implement this strategy and grow the intensity in their practice. This factor was found in other studies to be predictive of the implementation of guidelines on nursing diagnosis and intervention for patients with urinary incontinence (van der Weide \& Smits, 2004), and has been influential for public health nurses in their compliance to professional standards of practice (Oppewal, Lamanna, \& Lee Glenn, 2006). According to Rogers (2003), the basic notion of the compatibility attribute is that a new idea is perceived in relationship to existing practices that are already familiar to the individual. Rogers reminds us that change agents and others who introduce an innovation often commit an "empty vessel fallacy" by assuming that potential adopters are blank slates who lack any relevant experience with which to associate the new idea (Rogers). 
Mentoring and support were also shown to be specifically associated with increased intensity of the practice of starting women on hormonal contraception. Although the new practice could not be tested before the local CAHC was approved in the health organization, mentoring and support may have provided a "triability space" (Greenhalgh et al., 2004) easing implementation and assimilation of the new practice. It may have created a climate of confidence, especially if opinion leaders within the organization (which is the case in this study [Model 2 Intensity and supplemental data not shown]) were open to innovation and thus reflected a culture conducive to change. Further, it may have given the opportunity to more experienced nurse in transmitting tacit knowledge to junior or recently-graduated nurses or those who have previously worked in different fields. Indeed, past studies support the importance of mentoring and support in the implementation of new practices (Bowen, Stanton, \& Manno, 2012; Greenhalgh et al., 2004; Robert, Morrow, Maben, Griffiths, \& Callard, 2011; Rogers, 2003; van Achterberg et al., 2008).

Organizational characteristics played an important role in the results of this study and were more critically involved with implementation than delay and intensity. Voluntary decision to adopt the new practice, external openness and organizational innovativeness are all associated with the likelihood of implementation while structure of the organization is related to rapidity of adoption and organizational innovativeness and voluntary decision to adopt the new practice are associated with intensity. Concerning the type of decision involved in the process of implementing an innovation, implementation project leaders tend to prefer that professionals exert voluntary, intrinsic motivation-focused strategies in their acceptation of the new practice (Robert et al., 2011; van Achterberg et al., 2008). However, other types of decision (collective, authority decisions) may also lead to successful implementation (Rogers, 2003; van Achterberg et al. 2008). In light of the data from this study, we hypothesize that voluntary decisionmaking reinforced implementation because this new practice represented a response to values and desire for professional autonomy of nurses. In contrast, we postulate that its negative influence on intensity may be related to the work load of nurses who may wish to implement this practice but have limited time to do so in the face of other priorities (immunization, patients with chronic illnesses, etc.). Thus, voluntary decision-making is a "double-edged sword" in this experience and other types of decision-making could be investigated when introducing such innovative practices.

In line with other reports, organizational innovativeness was identified as a leading factor in voluntary decision-making and implementation (Greenhalgh et al., 2004; Oppewal, et al., 2006; Robert et al., 2011; Rogers, 2003; van Achterberg et al., 2008; While \& Biggs, 2004). The aspects of organizational innovativeness included low centralized decision-making and "organizational slack" - availability of premises, nurse and physician availability, access to pharmaceutical drug samples (useful for counseling), absence of professional isolation and technical support (results not shown). The more decentralized the decision-making and the greater the organizational slack, the more likely nurses were to implement this new practice and to be efficient. External openness or inter-organizational networking also had an influence on the implementation in our study like in other settings (Greenhalgh et al., 2004; Oppewal, et al., 2006; Robert et al., 2011; Rogers, 2003; van Achterberg et al., 2008; While \& Biggs, 2004).

The positive influence of opinion leaders both within and external to organizations must also be underscored as well as the mode of transmission of information which seemed to have a negative effect in terms of implementation and intensity. In the present study, nurses who favoured interpersonal contact to receive additional information on CAHC were less likely to implement the new practice. Additional analyses (not shown) indicated that such nurses lacked interpersonal contacts to obtain information on the new practice and would implement it only when others would do it. Such behaviour may have something to do with a certain level of anxiety or lack of confidence in performing the new tasks, as suggested in other studies (While \& Biggs, 2004). In the case of nurses who favoured electronic contact to receive additional information and implemented the new practice less intensively, additional analysis (not shown) pointed to a role for management responsibilities in addition to their clinical involvement.

\section{Study limitations}

This study has several limitations. First, although our sample size of this study was respectable, the response rate $(27 \%)$ was limited and may have been influenced by the fact that the study was launched around Christmas, a time when nurses were busy with flu immunization or were on vacation. Notably, in studies with larger sample sizes (Oppewal et al., 2006; Pestka, et al., 2010; Westrick, Watcharadamrongkun, Mount, \& Breland, 2009), the response rate was lower than in studies with small sample size (van der Weide \& Smits, 2004; While \& Biggs, 2004;). E-mail lists do not enable tracking of nurses who change organizations and sample selection bias due to recall errors and social desirability bias may also have been influential. We have no indication concerning the characteristics of nurses who did not participate in the survey; it is possible that they were less involved in this new practice and had no incentive to respond to a questionnaire. Such sample self-selection limits the extent to which the results of this study are applicable to all nurses who were trained in hormonal contraception. Rates of score variances in this study were $0.312,0.104$ and 0.425 for implantation, delay and intensity, respectively. In spite of offering insights on modifiable variables, these scores indicate that some of the variation (implementation and intensity) remained unexplained. The present study did not evaluate several other potentially important factors that may influence implementation and intensity, such as legitimacy of the source which proposes the innovation, cultural norms and values, organizational readiness for 
implementation, etc. (Damschroder et al., 2009; Greenhalgh et al., 2004; Meyers, Durlak, \& Wandersman, 2012; Robert et al., 2011; van Achterberg et al., 2008). Concerning delay of implementation, it is possible that Roger's theory may not be adequate for prediction. As suggested by Greenhalgh et al. (2004), evidence regarding the implementation of innovations is particularly complex and relatively sparse. Most studies concentrate on a handful of the components and, as such, generalizability of our study to other innovations or settings may be limited.

\section{CONCLUSION}

Service delivery is the heart of family planning programs. As proposed by Bongaarts, Cleland, Townsend, Bertrand and Gupta (2012), the health system should aim to deliver effective, safe, and high-quality care to those most in need, in a way that is acceptable to the individuals and communities served while also being efficient in the use of resources. However, many challenges remain. At the level of the implicated professionals, one major challenge is that: "task shifting should not be task piling... We need to ensure that task shifting happens in a team..." (Dambisya \& Matinhure, 2012). At the level of organizations, it appears important to envision capacity-building to facilitate the implementation of innovation, especially when there is a concurrent implementation of various innovations. Similarly, a Cochrane Review on the substitution of doctors by nurses in primary care (Laurant et al., 2005) indicates that doctors' workload may remain unchanged either because nurses are deployed to meet previously unmet patient needs or because nurses generate new demand for care where previously there was none. Nevertheless, monitoring progress and exploring the factors influencing implementation and how implementation impacts performance of the intervention may help progress toward implementation goals (Damschroder et al., 2009). In this particular case, it appears that along with the availability of a provincial drug insurance plan since 1998, availability of levonorgestrel intrauterine devices since 2000, direct access to emergency contraception in pharmacies since 2000 and the implementation of CAHCs since 2007, abortion rates among women 15-19 years and 20-24 years of age, between 2004 and 2011 , have decreased by $24 \%(22.1-16.9$ per 1000$)$ and $15 \%$ (36.4-30.8 per 1000 ), respectively (Institut de la statistique du Québec, 2013). Similarly, the birth rate (2004-2011) among teens (15-19 years of age) has decreased by $15 \%$ (10.38.8 per 1000 ) (Institut national de santé publique du Québec, 2013). With the new avenues provided by this study, improvements of this task-shifting strategy are possible, keeping in mind that scaling up an innovation is a never-ending relationship building and partnership development activity. (World Health Organization, 2009b)

\section{REFERENCES}

Armstrong, K.A., \& Stover, M.A. (1994). SMART START: an option for adolescents to delay the pelvic examination and blood work in family planning clinics. Journal of Adolescent Health, 15(5), 389395. http://dx.doi.org/10.1016/1054-139X(94)90262-3 Medline:7947853

Aziz, F.A., \& Osman, A.A. (1999). Safety of intrauterine device insertion by trained nurse-midwives in the Sudan. Advances in Contraception, 15(1), 9-14. http://dx.doi.org/10.1023/ A:1006675226663 Medline:10794042

Bertrand, J., Hardee, K., Magnani, R., \& Angle, M. (1995). Access, quality of care and medical barriers in family planning programs. International Family Planning Perspectives, 21(2), 64-69, 74 http://dx.doi.org/10.2307/2133525

Black, A., Yang, Q., Wu Wen, S., Lalonde, A.B., Guilbert, E., \& Fisher, W. (2009). Contraceptive use among Canadian women of reproductive age: results of a national survey. Journal of Obstetrics and Gynaecology Canada, 31(7), 627-640. Medline:19761636

Bongaarts, J., Cleland, J., Townsend, J.W., Bertrand, J.T., \& Gupta, M.D. (2012). Family planning programs for the 21stcCentury: rationale and design. New York: Population Council.

Bowen, C.M., Stanton, M., \& Manno, M. (2012). Using Diffusion of Innovations Theory to implement the confusion assessment method for the intensive care unit. Journal of Nursing Care Quality, 27(2), 139-145. http://dx.doi.org/10.1097/ NCQ.0b013e3182461eaf Medline:22367153

Cazale, L. \& Leclerc, P. (2010). Comportements sexuels et usage de contraception. L'Enquête québécoise sur la santé de la population, 2008: pour en savoir plus sur la santé des québécois. Pp. 173-187. Québec: Institut de la statistique du Québec.

Centers for Disease Control and Prevention (CDC). (2010). U.S. medical eligibility criteria for contraceptive use, 2010. MMRW. Morbidity and mortality weekly report, 59(RR-4 No. RR-4), 1-86. Medline:20559203

Centers for Disease Control and Prevention (CDC). (2011). Update to CDC's U.S. medical eligibility criteria for contraceptive use, 2010: revised recommendations for the use of contraceptive methods during the postpartum period. MMWR. Morbidity and mortality weekly report, 60(26), 878-883. Medline:21734635

Centers for Disease Control and Prevention (CDC). (2012). Update to CDC's U.S. medical eligibility criteria for contraceptive use, 2010: revised recommendations for the use of hormonal contraception among women at high risk for HIV infection or infected with HIV. MMWR. Morbidity and mortality weekly report, 61(24), 449-452. Medline:22717514

College of Family Physicians of Canada. (2005). The role of the family doctor in public health and emergency preparedness: a discussion paper.

College of Family Physicians of Canada \& The Canadian Medical Association. (2008). And still waiting:exploring primary care wait times in Canada. The College of Family Physicians of Canada and The Canadian Medical Association. [Announcement posted on the World Wide Web]

Dambisya, Y.M., \& Matinhure, S. (2012). Policy and programmatic implications of task shifting in Uganda: a case study. BMC Health Services Research, 12(1), 61. http://dx.doi.org/10.1186/1472-696312-61 Medline:22409869 
Damschroder, L.J., Aron, D.C., Keith, R.E., Kirsh, S.R., Alexander, J.A., \& Lowery, J.C. (2009). Fostering implementation of health services research findings into practice: a consolidated framework for advancing implementation science. Implementation Science; IS, 4(1), 50. http://dx.doi.org/10.1186/1748-5908-4-50 Medline: 19664226

Dubé-Linteau, A., Pineault, R., Lévesque, J.F., Lecours, C., \& Tremblay, M.-È. (2013). Enquête québécoise sur l'expérience de soins 2010-2011. Le médecin de famille et l'endroit habituel de soins: regard sur l'expérience vécue par les Québécois (Vol. 2). Québec: Institut de la statistique du Québec.

Eren, N., Ramos, R., \& Gray, R.H. (1983). Physicians vs. auxiliary nurse-midwives as providers of IUD services: a study in Turkey and the Philippines. Studies in Family Planning, 14(2), 43-47. http://dx.doi.org/10.2307/1965401 Medline:6836665

Farr, G., Rivera, R., \& Amatya, R. (1998). Non-physician insertion of IUDs: clinical outcomes among TCu380A insertions in three developing-country clinics. Advances in Contraception, 14(1), 4557. http://dx.doi.org/10.1023/A:1006575610716 Medline:9587008

Gardner, J.S., Miller, L., Downing, D.F., Le, S., Blough, D., \& Shotorbani, S. (2008). Pharmacist prescribing of hormonal contraceptives: results of the Direct Access study. Journal of the American Pharmacists Association, 48(2), 212-221. http:// dx.doi.org/10.1331/JAPhA.2008.07138 Medline:18359734

Gladu, F.P. (2007). Perceived shortage of family doctors in Quebec: can we do something about it? Canadian Family Physician Médecin de famille canadien, 53(11), 1858-1860, 1871-1873. Medline: 18000244

Goldman, K.D. (1994). Perceptions of innovations as predictors of implementation levels: the diffusion of a nationwide health education campaign. Health Education Quarterly, 21(4), 433-445. http://dx.doi.org/10.1177/109019819402100406 Medline:7843976

Gouvernement du Québec (2002). Projet de loi numéro 90, loi modifiant le Code des professions et d'autres dispositions législatives dans le domaine de la santé. Assemblée nationale, Gouvernement du Québec [Announcement posted on the World Wide Web]. http://www2.publicationsduquebec.gouv.qc.ca/ dynamicSearch/telecharge.php?type $=5 \&$ file $=2002$ C33F.PDF

Gouvernement du Québec (2013). Loi sur la pharmacie (Rep. No. 145e année, no 4). Québec: Gazette officielle du Québec.

Greene, W.H. (2012). Econometric Analysis, 71E. Stern School of Business, New York University. [Announcement posted on the World Wide Web]

Greenhalgh, T., Robert, G., Macfarlane, F., Bate, P., \& Kyriakidou, O. /given-names $>$ (2004). Diffusion of innovations in service organizations: systematic review and recommendations. Milbank Quarterly, 82(4), 581-629. http://dx.doi.org/10.1111/j.0887378X.2004.00325.x Medline:15595944

Groulx, S. \& Direction de santé publique de l'Agence de la santé et des services sociaux de la Montérégie (2007). Guide pour la promotion et le soutien des pratiques cliniques préventives. Santé et services sociaux du Québec [Announcement posted on the World Wide Web].

Guilbert, E.R., Guilbert, A.C., Risi, C., Gendron, F., Bérubé, J., Charbonneau, L., Ouellet, S., Roy, G., \& Wagner, M.-S. (2011). Portrait des ordonnances collectives de contraception hormonales adoptées au Québec. Institut national de santé publique du Québec [Announcement posted on the World Wide Web].
Guilbert E.R., Ménard C., Mercier C., \& Caron M. (2007). L’engagement des ordres professionnel et de la santé publique pour réduire les grossesses non planifiées. Le point en Administration de la Santé et des Services Sociaux, 3(3), 26-28.

Guilbert, E.R., Morin, D., Guilbert, A.C., Gagnon, H., Robitaille, J., \& Richardson, M. (2011). Task-shifting in the delivery of hormonal contraceptive methods: validation of a questionnaire and preliminary results. International Journal of Nursing Practice, 17(3), 315-321. http://dx.doi.org/10.1111/j.1440-172X.2011.01939.x Medline:21605273

Guilbert, E.R., Robitaille, J., Guilbert, A.C., Morin, D., \& Group of Experts in Family Planning of the National Institute of Public Health of Quebec. (2013). Challenges of implementing taskshifting in contraceptive care-an experience in Quebec, Canada. Contraception, 88(5), 587-590. http://dx.doi.org/10.1016/j. contraception.2013.07.004 Medline:24018140

Guilbert, E.R., Rousseau, M., Guilbert, A.C., Robitaille, J., Gagnon, H., \& Morin, D. (2013). Process evaluation of a task-shifting strategy in hormonal contraception: does training translate into practice? Journal of Obstetrics and Gynaecology Canada, 35(12), 1090-1100. Medline:24405876

Harper, C., Balistreri, E., Boggess, J., Leon, K., \& Darney, P. (2001). Provision of hormonal contraceptives without a mandatory pelvic examination: the first stop demonstration project. Family Planning Perspectives, 33(1), 13-18. http://dx.doi.org/10.2307/ 2673737 Medline:11271540

Hoddinott, S.N., \& Bass, M.J. (1986). The dillman total design survey method. Canadian Family Physician Médecin de famille canadien, 32, 2366-2368. Medline:21267217

Hoke, T.H., Wheeler, S.B., Lynd, K., Green, M.S., Razafindravony, B.H., Rasamihajamanana, E., \& Blumenthal, P.D. (2012). Community-based provision of injectable contraceptives in Madagascar: 'task shifting' to expand access to injectable contraceptives. Health Policy and Planning, 27(1), 52-59. http:// dx.doi.org/10.1093/heapol/czr003 Medline:21257652

Institut de la statistique du Québec (2013). Interruptions volontaires de grossesse, hystérectomies et stérilisations, par groupe d'âge, Québec 1976-2011.

Institut national de santé publique du Québec (2013). Taux de grossesse selon l'âge, 2004-2011 Québec, Canada.

Janowitz, B., Stanback, J., \& Boyer, B. (2012). Task sharing in family planning. Studies in Family Planning, 43(1), 57-62. http:// dx.doi.org/10.1111/j.1728-4465.2012.00302.x Medline:23185872

Jejeebhoy, S.J., Kalyanwala, S., Zavier, A.J., Kumar, R., Mundle, S., Tank, J., ..., \& Jha, N. (2011). Can nurses perform manual vacuum aspiration (MVA) as safely and effectively as physicians? Evidence from India. Contraception, 84(6), 615-621. http:// dx.doi.org/10.1016/j.contraception.2011.08.010 Medline:22078191

Lassner, K.J., Chen, C.H.C., Kropsch, L.A.J., Oberle, M.W., Lopes, I.M.N., \& Morris, L. (1995). Comparative study of safety and efficacy of IUD insertions by physicians and nursing personnel in Brazil. Bulletin of the Pan American Health Organization, 29(3), 206-215. Medline:8520606

Laurant, M., Reeves, D., Hermens, R., Braspenning, J., Grol, R., \& Sibbald, B. (2005). Substitution of doctors by nurses in primary care. Cochrane Database of Systematic Reviews, (2): CD001271. Medline:15846614 
Lewis, L.K., \& Seibold, D.R. (1993). Innovation modification during intra-organizational adoption. Academy of Management Review, $18,322-354$

Meyers, D.C., Durlak, J.A., \& Wandersman, A. (2012). The quality implementation framework: a synthesis of critical steps in the implementation process. American Journal of Community Psychology, 50(3-4), 462-480. http://dx.doi.org/10.1007/s10464-0129522-x Medline:22644083

Montufar, E., Morales, C., Vernon, R., Brambila, C., \& Solorzano, J. (2005). Improving access to long-term contraceptives in rural Guatemala through the Ministry of Health. New York: Population Council.

Mullany, L.C., Lee, T.J., Yone, L., Lee, C.I., Teela, K.C., Paw, P. , ..., \& Beyrer, C. (2010). Impact of community-based maternal health workers on coverage of essential maternal health interventions among internally displaced communities in eastern Burma: the MOM project. PLoS Medicine, 7(8), e1000317. http://dx.doi.org/ 10.1371/journal.pmed.1000317 Medline:20689805

Mwaikambo, L., Speizer, I.S., Schurmann, A., Morgan, G., \& Fikree, F. (2011). What works in family planning interventions: a systematic review. Studies in Family Planning, 42(2), 67-82. http:// dx.doi.org/10.1111/j.1728-4465.2011.00267.x Medline:21834409

Oppewal, S., Lamanna, B.F., \& Lee Glenn, L. (2006). Comparison of the dissemination and implementation of standardized public health nursing competencies in academic and practice settings. Public Health Nursing (Boston, Mass.), 23(2), 99-107. http:// dx.doi.org/10.1111/j.1525-1446.2006.230202.x Medline:16684185

Ordre des infirmières et infirmiers du Québec. (2007a). Formulaire d'évaluation de l'infirmière pour initier la contraception hormonale. 1-9. Montreal, Quebec, Canada., Ordre des infirmières et infirmiers du Québec.

Ordre des infirmières et infirmiers du Québec. (2007b). Guide de rédaction d'une ordonnance collective de contraception hormonale. Ordre des infirmières et infirmiers du Québec, 1-18.

Ordre des infirmières et infirmiers du Québec. (2009a). Formulaire d'évaluation de l'infirmière pour initier la contraception hormonale. 1-9. Montréal, Québec, Canada, Ordre des infirmières et infirmiers du Québec.

Ordre des infirmières et infirmiers du Québec. (2009b). Guide de rédaction d'une ordonnance collective de contraception hormonale. Ordre des infirmières et infirmiers du Québec, 1-18.

Ordre des infirmières et infirmiers du Québec. (2012a). Formulaire d'évaluation de l'infirmière pour intier la contraception hormonale ou le stérilet. 1-9. Montréal, Québec, Canada, Ordre des infirmières et infirmiers du Québec.

Ordre des infirmières et infirmiers du Québec. (2012b). Guide de rédaction d'une ordonnance collective de contraception hormonale et de stérilet. Ordre des infirmières et infirmiers du Québec, $1-22$.

Parsons, J., Adams, C., Aziz, N., Holmes, J., Jawad, R., \& Whittlesea, C. (2013). Evaluation of a community pharmacy delivered oral contraception service. Journal of Family Planning and Reproductive Health Care, 39(2), 97-101. http://dx.doi.org/10.1136/jfprhc2012-100304 Medline:22923279

Pestka, E.L., Derscheid, D.J., Ellenbecker, S.M., Schmid, P.J., O’Neil, M.L., Ray-Mihm, R.J., \& Cox, D.L. (2010). Use of genomic assessments and interventions in psychiatric nursing practice.
Issues in Mental Health Nursing, 31(10), 623-630. http:// dx.doi.org/10.3109/01612840.2010.493266 Medline:20854035

Robert, G., Morrow, E., Maben, J., Griffiths, P., \& Callard, L. (2011). The adoption, local implementation and assimilation into routine nursing practice of a national quality improvement programme: the Productive Ward in England. Journal of Clinical Nursing, 20(7-8), 1196-1207. http://dx.doi.org/10.1111/j.13652702.2010.03480.x Medline:21320218

Robitaille, J. (2011). Sample Size Solver 2.0. Quebec, Canada: Laval University. [Announcement posted on the World Wide Web]

Rogers, E.M. (2003). Diffusion of innovations. (5th ed.) New York: Free Press.

Rogers, E.M., Vaughan, P.W., Swalehe, R.M., Rao, N., Svenkerud, P., \& Sood, S. (1999). Effects of an entertainment-education radio soap opera on family planning behavior in Tanzania. Studies in Family Planning, 30(3), 193-211. http://dx.doi.org/10.1111/ j.1728-4465.1999.00193.x Medline:10546311

Rosenbaum, J., \& Lidz, C.W. (2007). Maximizing the results of internet surveys. Psychiatry Information in Brief, (4)2, 1-2.

Stanback, J., Mbonye, A.K., \& Bekiita, M. (2007). Contraceptive injections by community health workers in Uganda: a nonrandomized community trial. Bulletin of the World Health Organization, 85(10), 768-773. http://dx.doi.org/10.2471/ BLT.07.040162 Medline:18038058

Statistics Canada. (2010). Induced abortions in hospitals and clinics, by area of residence of patient, Canada, provinces and territories, annual - Year 2006.

Traoré, E. \& Cazale, L. (2008). Qui n’a pas de médecin de famille au Québc? Portraits \& Trajectoires, 1-2. Institut de la statistique du Québec.

Vaillant, H.W., Cummins, G.T.M., Richart, R.M., \& Barron, B.A. (1968). Insertion of Lippes loop by nurse-midwives and doctors. British Medical Journal, 3(5619), 671-673. http://dx.doi.org/ 10.1136/bmj.3.5619.671 Medline:5673217

van Achterberg, T., Schoonhoven, L., \& Grol, R. (2008). Nursing implementation science: how evidence-based nursing requires evidence-based implementation. Journal of Nursing Scholarship, 40(4), 302-310. http://dx.doi.org/10.1111/j.15475069.2008.00243.x Medline:19094144

van der Weide, M., \& Smits, J. (2004). Adoption of innovations by specialised nurses: personal, work and organisational characteristics. Health Policy (Amsterdam), 68(1), 81-92. http://dx.doi.org/ 10.1016/j.healthpol.2003.09.007 Medline:15033555

Warriner, I.K., Meirik, O., Hoffman, M., Morroni, C., Harries, J., My Huong, N.T., ..., \& Seuc, A.H. (2006). Rates of complication in first-trimester manual vacuum aspiration abortion done by doctors and mid-level providers in South Africa and Vietnam: a randomised controlled equivalence trial. Lancet, 368(9551), 1965-1972. http://dx.doi.org/10.1016/S0140-6736(06)69742-0 Medline: 17141703

Warriner, I.K., Wang, D., Huong, N.T., Thapa, K., Tamang, A., Shah, I. , ..., \& Meirik, O. (2011). Can midlevel health-care providers administer early medical abortion as safely and effectively as doctors? A randomised controlled equivalence trial in Nepal. Lancet, 377(9772), 1155-1161. http://dx.doi.org/10.1016/S01406736(10)62229-5 Medline:21458058 
Welsh, M.J., Stanback, J., \& Shelton, J. (2006). Access to modern contraception. Best Practice \& Research. Clinical Obstetrics \& Gynaecology, 20(3), 323-338. http://dx.doi.org/10.1016/j. bpobgyn.2005.12.001 Medline:16443395

Westrick, S.C., Watcharadamrongkun, S., Mount, J.K., \& Breland, M.L. (2009). Community pharmacy involvement in vaccine distribution and administration. Vaccine, 27(21), 2858-2863. http:// dx.doi.org/10.1016/j.vaccine.2009.02.086 Medline:19428895

While, A.E., \& Biggs, K.S.M. (2004). Benefits and challenges of nurse prescribing. Journal of Advanced Nursing, 45(6), 559-567. http:// dx.doi.org/10.1046/j.1365-2648.2003.02948.x Medline:15012633
World Health Organization. (2009a). Medical eligibility criteria for contraceptive use. Geneva, Switzerland: World Health Organization. [Announcement posted on the World Wide Web]

World Health Organization. (2009b). Pratical guidance for scaling up health service innovations. World Health Organization. [Announcement posted on the World Wide Web]

World Health Organization \& UNAIDS. (2007). Task shifting: global recommendations and guidelines: treat, train, retain. World Health Organization. [Announcement posted on the World Wide Web] 
Reproduced with permission of the copyright owner. Further reproduction prohibited without permission. 